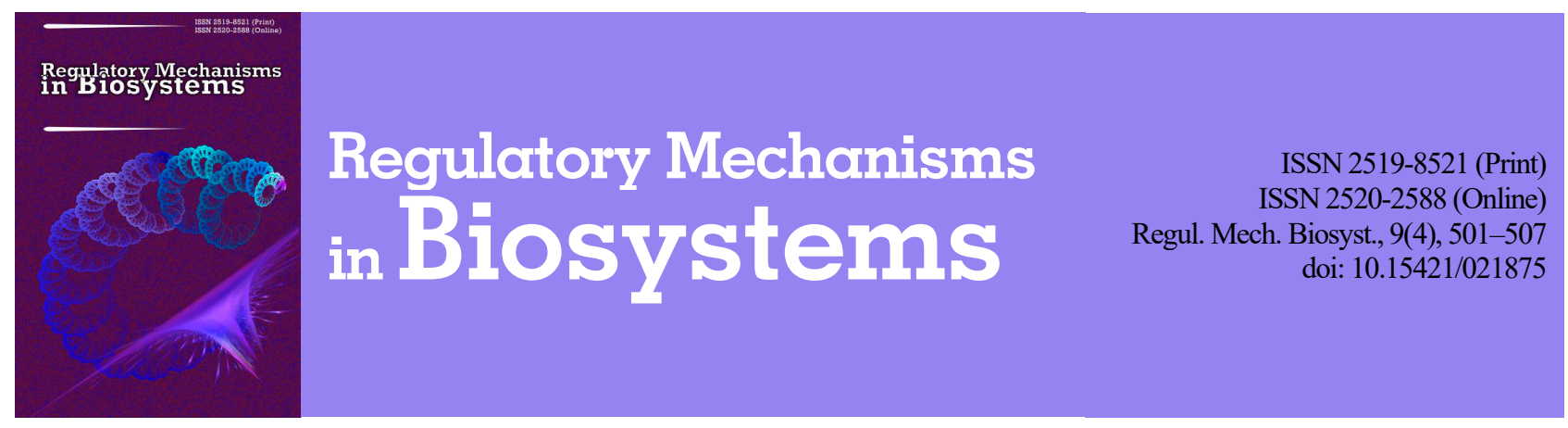

\title{
Soluble curcumin prevents cadmium cytotoxicity in primary rat astrocytes by improving a lack of GFAP and glucose-6-phosphate-dehydrogenase
}

\author{
V. S. Nedzvetsky***, E. V. Sukharenko*, S. V. Kyrychenko**, G. Baydas*** \\ *Bingöl University, Bingöl, Turkey \\ **Oles Honchar Dnipro National University, Dnipro, Ukraine \\ ***Altinbas University, Istanbul, Turkey
}

Article info

Received 04.10.2018

Received in revised form 29.10.2018

Accepted 07.11.2018

Bingöl University, Bingöl,

Turkey, Selahaddin-i Eyyubi

Mah. Üniversite Cad. No. 1 ,

Bingöl, 12000, Turkey.

Tel.: +90-426-216-00-12.

Oles Honchar Dnipro

National University

Gagarin av., 72

Dnipro, 49010, Ukraine.

E-mail:svetavk@ukr.net

Altinbas University, Istanbul, Turkey, Mahmetbey

Dilmenler, Caddesi 26

Bagcilav, Istanbul,

34217, Turkey.

Tel.: +90-532-312-52-01.

Nedzvetsky, V. S., Sukharenko, E. V., Kyrychenko, S. V., \& Baydas, G. (2018). Soluble curcumin prevents cadmium cytotoxicity in primary rat astrocytes by improving a lack of GFAP and glucose-6-phosphate-dehydrogenase. Regulatory Mechanisms in Biosystems, 9(4), 501-507. doi:10.15421/021875

Cadmium $(\mathrm{Cd})$ is a heavy metal which is widespread in various environmental components. Moreover several occupational diseases have the complications that are related to $\mathrm{Cd}$ cytotoxicity. Low doses of $\mathrm{Cd}$ exposure could induce pathogenetic disturbances in several sensitive cells as result of its long biological half-life and accumulation in vital tissue types. Prolonged Cd exposure was determined as main factor in accumulation of this metal ion over time in the liver, kidneys and neural tissue cells. The neurotoxic effect of $\mathrm{Cd}$ was presented in several articles which reported both in vivo and in vitro study. One of the main causes of Cd neurotoxicity is the ability of this ion to increase the permeability of the blood brain barrier. Despite a focus of attention on $\mathrm{Cd}$ cytotoxicity over the last few decades, the effect of $\mathrm{Cd}$ in neural tissue cells has been presented in a limited number of articles. The neurotoxic effect of $\mathrm{Cd}$ is accompanied by biochemical changes as well as a lack of functional activity of the central nervous system. Taking into account that the cytotoxic effect of $\mathrm{Cd}$ is associated with oxidative stress, inflammation and selective cell death, antioxidants could be used to protect neural tissue cells against both chronic and acute $\mathrm{Cd}$ exposure. Antioxidants protect diverse cell types against metal induced cytotoxicity. Curcumin is a natural polyphenol which exhibits antioxidant and anti-inflammatory effect. Soluble forms of cucrcumin can penetrate the blood brain barrier and protect neural tissue cells against detrimental effects of cytotoxic compounds. Glial cells are the most numerous cell population in CNS. Astrocytes possess the ability to protect the neuronal cells against cytotoxicity and maintain CNS functions. The cytoskeleton of astrocytes is constructed with glial fibrillary acidic protein (GFAP). GFAP is involved in essential functions of astrocytes and reflects astrocyte reactivity. The molecular mechanisms of the neurotoxic effect of $\mathrm{Cd}$ on glial cytoskeleton remain unknown. Primary astrocyte cell culture was used as model to assess the gliotoxic effect of $\mathrm{Cd}$ as well as the potency of low doses of soluble curcumin to ameliorate the neurotoxic effect of $\mathrm{Cd}$. The obtained results demonstrated depletion of GFAP and glucose-6-phosphate-dehydrogenase (G6PD) in astrocytes treated with $10 \mu \mathrm{M} \mathrm{Cd}$. The exposure to $5 \mu \mathrm{M}$ curcumin ameliorated the expression both of GFAP and G6PD in Cd suppressed astrocytes. Moreover, low doses of soluble curcumin significantly prevented the detrimental effects of $\mathrm{Cd}$ on cell viability and indices of oxidative stress. The obtained results are evidence that soluble forms of curcumin improve astrocyte viability, cytoskeleton depletion and glucose utilization pathway. Thus, soluble curcumin possesses a neuroprotective effect directed on astrocyte cytoskeleton and metabolic energy production.

Keywords: cadmium neurotoxicity; soluble curcumin; neuroprotection; astrocytes; glial fibrillary acidic protein; glial cytoskeleton

\section{Introduction}

The toxicity of cadmium $(\mathrm{Cd})$ ions has attracted special attention over recent decades. This heavy metal is a ubiquitous pollutant and enters the environment continuously from industrial and agricultural sources (Van Maele-Fabry et al., 2016). New detrimental effects of Cd have been discovered in the last few decades, cadmium having been classified as a human carcinogen by the International Agency for Research on Cancer (IARC) (Waisberg et al., 2003). Cd exposure may initiate several deleterious consequences on practically every vital system. Quantified data have demonstrated that $\mathrm{Cd}$ exposure can cause nonreversible damages in vertebrates. Various doses of $\mathrm{Cd}$ as well as both acute and chronic exposure are considered to induce key pathways disturbance into the vital tissues, including the heart, liver, kidney and brain (Järup \& Akesson, 2009; Nair et al., 2013; Ninkov et al., 2015). There is variation in the sensitivity of individual tissues to $\mathrm{Cd}$ induced damage (Swiergosz-Kowalewska, 2001). The liver and kidneys are among the vital organs recognized as most sensitive to $\mathrm{Cd}$ toxicity (Järup et al., 2009). The toxic effect of $\mathrm{Cd}$ has been studied in detail over the last few decades, especially in the liver and kidneys (Fujiwara et al., 2012; Baiomy et al., 2016). In several tissues of the human body the half-life of $\mathrm{Cd}$ is extremely long at from 10-30 years (Fujiwara et al., 2012). This provides evidence that both chronic and acute Cd exposure can cause the accumulation of this heavy metal in the cells of vital tissues (Wang \& Du, 2013). Even in low doses, Cd exposure has a detrimental effect, accumulating in vital organs and with wide environmental and industrial distribution, this ion is considered as an extremely poisonous pollutant. $\mathrm{Cd}$ induces cell death via the initiation of various apoptotic pathways which are induced through the stress of endoplasmic reticulum, intracellular calcium release as well as mitochondria-mediated pathways of cell death switching (Nilesh et al., 2009). Recently, Lee and coauthors demonstrated both in vitro and in vivo the effect of $\mathrm{Cd}$ toxicity on p53dependent apoptotic cell death, which plays a key role in renal proximal tubules (Lee et al., 2016). Among the many cell types which are the targets of $\mathrm{Cd}$, the brain remains insufficiently studied.

Cd toxicity in neural tissue cells has been presented in a limited number of articles only. The neurotoxic effect of $\mathrm{Cd}$ in children was 
investigated in the 1970-1980s, but unfortunately the obtained results have received little attention since then. Recently, Phuagkhaopong and coauthors showed the evidence of Cd accumulation in U-87 MG astrocytoma cells model (Phuagkhaopong et al., 2017). Moreover, 24 hours exposure $10 \mu \mathrm{M} \mathrm{CdCl}_{2}$ induced morphology disturbance of these glial cells and stimulated proinflammatory cellular response following IL-6 and IL-8 release. Neuroinflammation plays a key role in pathogenesis of many CNS disorders including neurodegeneration (Liu et al., 2014). In addition, a recent epidemiological study presented the results of significant association between high levels of $\mathrm{Cd}$ in the blood and learning disabilities (Ciesielski et al., 2012). Another study of adults demonstrated the relation of cadmium exposure with decreased performance in neurobehavioral tasks which require attention and perception (Ciesielski et al., 2013). Moreover, recently the presence of human subpopulations sensitive to $\mathrm{Cd}$ exposure was determined in a normative aging study (Ciesielski et al., 2018). These sensitive subpopulations are recognized as cadmium risk groups which have more intensive $\mathrm{Cd}$ absorption from their environment caused by diet and hemoglobin homozygote genotype. Thus, Cd toxicity may be at least partially involved in CNS disorders as well as in the progress of cognitive impairment. The mechanism to initiate a large number of Cd-induced complications may involve oxidative stress generation as well as other heavy metal ions (Farina et al., 2013). Recently, tissue-specific effects of Cd toxicity were demonstrated in chronic treatment in vivo. The authors note that the differential modulation of transcription factors could determine specific differences in gene expression in various tissues or cell lines (Lee et al., 2016).

Despite a number of studies of Cd cytotoxicity in the liver, the mechanisms of $\mathrm{Cd}$ neurotoxicity remain unknown (Mendez-Armenta $\&$ Rios, 2007). However, recent data have shown that the toxic effect of $\mathrm{Cd}$ could be directed preferably to glial cell functions (Mori et al., 2015). Yet, there is limited data concerning the effects of Cd toxicity in astroglial cells. Astrocytes are the most abundant glial population as well as prevalent cell type in mammalian CNS (Buosi et al., 2018). Astrocytes are multifunctional cells which maintain brain homeostasis by ensuring neuron viability and defending it against cytotoxic injury. Strokes and other types of damage induce in astrocytes a special manner of response referred to as "reactive astrogliosis" (Pekny et al., 2013). This response is directed to restore damaged brain areas and neuronal functions. Astrogliosis is accompanied by a large range of glial cells reactivity from mild to strong proliferation in stimulus-dependent manner. Several initiators can induce cytokine overproduction, which together with activated microglia cells provides neuroinflammation (Owens et al., 2017). Moreover, upregulation of glial reactivity may lead to functional disturbances and permeability of the blood brain barrier (BBB) (Neuhaus et al., 2014). Thus, the neurotoxic features of several compounds can be determined by the control of astroglial reactivity in functional interaction neuron-glia-endothelial cell. Cd toxicity can trigger apoptosis in brain endothelial cells via the induction of mitogen activated protein kinase (MAPK) upregulation (Jung et al., 2008).

Another pathway of Cd cytotoxic effect may be mediated through generation of oxidative stress in glial cells and the disturbance of intracellular $\mathrm{Ca}^{2+}$ balance (Yang et al., 2008). Thus, Cd exposure could be a multifaceted factor which leads to oxidative stress and pro-inflammatory reactivity in neural tissue cells. As a rule, cadmium induces ROS generation indirectly through the inhibiting antioxidant systems, especially catalase, superoxide dismutase, glutathione peroxidase, and glutathione reductase (Shukla et al., 1989; Acan et al., 1995). Moreover, Cd can suppress non-enzyme antioxidant defense. Im and coauthors presented data that $\mathrm{CdSO}_{4}$ in a range $10-30 \mu \mathrm{M}$ doses initiated cell death in primary cortical astrocytes culture and glutathione depletion (Im et al., 2006). In this study, the authors demonstrated that the non linear sigmoid depends on both time- and dose-dependent Cd cytotoxicity.

The effectiveness of antioxidants and free radical scavengers have been recognized to protect various cell types against cadmium induced cytotoxicity including pituitary cells, brain and liver tissue (Poliandri et al., 2003; Tandon et al., 2003). Recently, the protective effect of curcumin has been demonstrated in the liver damaged with hepatotoxic inducers including arsenic, cadmium, chromium, copper, lead and mercury ions. In this study, curcumin prevented lipid peroxidation, glutathione depleti- on, both antioxidant enzymes and mitochondrial dysfunction. Curcumin or diferuloylmethane (1,7-bis(4-hydroxy-3-methoxyphenyl)-1,6-heptadiene-3,5-dione) is a polyphenol natural compound extracted from the rhizome of Curcuma longa (García-Niño et al., 2014). Curcumin is known as turmeric and is used as a dietary spice and food colouring agent. Curcumin is the main component of turmeric and exhibits antioxidant (Al-Jassabi et al., 2012; Mohajeri et al., 2017), anti-inflammatory (Bereswill et al., 2010) antiviral (Kutluay et al., 2008), antimicrobial (Marini et al., 2008) and anti-tumour properties (Wang et al., 2009; Huang et al., 2013). Curcumin is well known as a multifaceted plant compound with anti-inflammatory effect. This polyphenol possess the ability to inhibit the generation of pro-inflammatory factors through transcriptional control in both transformed and normal cell types (Strasser et al., 2005; Fattori et al., 2015; Hsu et al., 2015; Rajitha et al., 2016; Tong et al., 2016). Moreover, curcumin develops cytoprotective features in injured neural tissue (Tu et al., 2014; Chang et al., 2015). Unfortunately, the physico-chemical proprieties of curcumin significantly limit its penetration through the BBB. However, modern technology has made it possible to produce a water soluble curcumin fraction that can easy cross the BBB and reach into brain cells (Purkayastha et al., 2009). Unfortunately, curcumin exhibits poor bioavailability as result of its hydrophobic nature and poor water-solubility (Priyadarsini, 2014). Numerous approaches have been tested to improve both the bioavailability and the solubility of curcumin. Researchers have obtained positive results by using several derivates including natural analogues from turmeric, other plant natural analogues, synthetic analogues, liposomes and nanoparticles containing curcumin (Taylor et al., 2011; Liu et al., 2012; Yogosawa et al., 2012; Bhullar et al., 2013). In the work presented here we used a soluble fraction of natural curcumin produced by Sencient corporation to build up the cell culture model of astrocyte targeting by neuroprotection with curcumin.

The cytoskeleton of eukariotic cells takes part in a number of vital processes, especially in cellular response to cytotoxic metal ions exposure (Nedzvetsky et al., 2006). Besides, the cytoskeleton is a dynamic structure which provides both cell shape and intracellular regulatory pathways (Specification \& Freeman, 2010; Kamphuis et al., 2015). Glial cells are considered as the major and numerous population in brain tissue. Astrocytes and microglial cells possess the ability to defend neurones against cytotoxicity and maintain many neuronal functions. Cytoskeleton of astrocytes contains intermediate filaments constructed with glial specific subunit glial acidic fibrillary protein (GFAP). GFAP is involved in most key functions of astrocytes and is a well known marker of astrocyte reactivity (Eng et al., 2000). Cd neurotoxicity could relate to the molecular machinery of cytoskeleton rearrangement in the adult brain as well as astrocyte vital functions. Taking into account the complex cytoprotective effects of curcumin, one of them could be directed to prevent glial cytoskeleton disturbance. Unfortunately, the neurotoxic effects of $\mathrm{Cd}$ on glial cytoskeleton rearrangement as well as neuroprotective features of natural polyphenols remain unknown.

The aim of our work was to elucidate the cytoskeleton changes induced with low doses of $\mathrm{Cd}$ in primary astrocyte cell culture and to estimate the glioprotective effect of the soluble form of curcumin.

\section{Materials and methods}

Culture of rat primary astrocytes. Rat primary astrocyte cell culture was prepared as previously described (Nedzvetsky et al., 2017). Briefly, brain hemispheres were isolated from newborn (1-2 days old) SpragueDawley rats of both sexes. The brain tissue was softly dissociated mechanically and incubated in $0.1 \%$ trypsin-containing Henk's solution at $37^{\circ} \mathrm{C}$ for $5 \mathrm{~min}$ for dissociation of cells. The digesting with trypsin was stopped by addition trice volume of DMEM culture medium containing $10 \%$ FBS and antibiotics. Then soft trypsinization tissue was passed through a $135 \mu \mathrm{m}$ nylon sieve. The pellet of cells was washed with fivefold volume Hank's solution, re-suspended and centrifuged at 1,500 rpm for $5 \mathrm{~min}$. The obtained cell pellet was next re-suspended in DMEM containing 10\% fetal bovine serum, $25 \mathrm{mM}$ glucose, $1 \%$ L-glutamine, $1 \%$ sodium pyruvate, and $1 \%$ penicillin-streptomycin. The cells were seeded onto a $75 \mathrm{~cm}^{2}$ cell culture flask in this medium and cultured at 
$37^{\circ} \mathrm{C}$ in a humidified $5 \% \mathrm{CO}_{2}$ atmosphere. The medium was renewed every two days during 12 days. In the last 3 days the cells were treated with shaking for $1 \mathrm{~h}$ at $150 \mathrm{rpm}$ with subsequent medium changing to remove the microglia cells. Culture purity was determined no less than $95 \%$ by immunocytochemistry using cell-type specific antibodies against GFAP for astrocytes and isolectin $\mathrm{B}_{4}$ for microglia cells (data not shown). After 12 days growth, the astrocytes were detached by trypsinization, centrifuged, dissociated in DMEM, and seeded into $7 \mathrm{~cm}$ Petri dishes at $10^{5}$ cells $/ \mathrm{cm}^{2}$ of compactness. Several days after the seeding of cells, when the confluence ran up to $70-80 \%$, the astrocytes were incubated overnight in medium without FBS. The next day the cells were treated with $\mathrm{Cd}(10 \mu \mathrm{M})$, curcumin $(2$ and $5 \mu \mathrm{M})$ and $\mathrm{Cd}$ with curcumin together for $48 \mathrm{~h}$. Stock solution of cadmium chloride $\left(\mathrm{CdCl}_{2}\right)$ was prepared by dissolving in sterile water at $100 \mathrm{mM}$ and stored in $20^{\circ} \mathrm{C}$. Curcumin stock solution was prepared via dissolving curcumin water soluble fraction (Curcumin L-WS E-100, Sensient Technologies Corporation, USA) in DMEM $4 \mathrm{mM}$ immediately before treatment. All chemicals except curcumin were from Sigma-Aldrich.

Cell viability test. The level of cell viability was measured via developing the capability of live cells to reduce 3-(4,5-dimethylthiazol-2-yl)2,5-diphenyltetrazolium bromide (MTT assay). The effect of Cd, curcumin and the combined effect both of them on primary astroglia cell viability were studied in various concentration of curcumin for $48 \mathrm{~h}$. Cells were collected from confluenced plates, suspended in DMEM complemented with $10 \% \mathrm{FBS}$ and diluted to concentration $10^{5} \mathrm{cells} / \mathrm{ml}$. The astrocytes were seeded into 96 -well plates at $2 \times 10^{4}$ cells/well and incubated for 12 hours at $37^{\circ} \mathrm{C}$ in a humidified atmosphere with $5 \% \mathrm{CO}_{2}$. After cell attachment and the start of growth in every well, the medium was changed and cells were exposed to $\mathrm{Cd}(10 \mu \mathrm{M})$ and various concentration of curcumin $(2$ and $5 \mu \mathrm{M})$ dissolved in the medium. Untreated (control) cells were not exposed to any solution. Concentrations of the tested substances were selected based on the literature data (Im et al., 2006; Mori et al., 2015; Lee et al., 2016). Every control and Cd, curcumin and $\mathrm{Cd}^{+}$curcumin exposure concentration was represented by three wells and replicated twice. The medium was removed from plates after $48 \mathrm{~h}$ incubation and the wells were rinsed with PBS. After washing, the solution containing $180 \mu \mathrm{l}$ PBS and $20 \mu \mathrm{l}$ MTT reagent was added into every well. The cells were incubated with MTT reagent $(0,5 \mathrm{mg} / \mathrm{ml}$ final concentration) for $4 \mathrm{~h}$ at $37^{\circ} \mathrm{C}$ in a humidified atmosphere with $5 \% \mathrm{CO}_{2}$. After incubation, the MTT solution was removed and $180 \mu \mathrm{l}$ DMSO was added in each well for 10 min following incubation. The absorbance level was measured in the presence of $20 \mu \mathrm{l}$ Sorensen's buffer at wavelength $570 \mathrm{~nm}$. The obtained data were presented as the percentage of control value.

Protein sample preparations and Western blot. The cells which were grown in Petri dishes were washed trice with the cold PBS after $48 \mathrm{~h}$ exposure and collected with scratching without trypsinization. The astrocytes were lysed in RIPA buffer containing proteinase and phosphotase inhibitor cocktail. Astrocyte proteins were extracted for $60 \mathrm{~min}$ at $4{ }^{\circ} \mathrm{C}$. The whole cell lysates were centrifuged at $40,000 \mathrm{~g}$ for $20 \mathrm{~min}$. The content of total protein in supernatants was measured with spectrophotometer by the Bradford (1976) method using BSA as the standard. The supernatant of each protein extract was diluted 1:1 in Laemmli Sample Buffer containing $0.1 \mathrm{M}$ dithiothreitol, and boiled for $5 \mathrm{~min}$. The obtainned protein samples were frozen and stored at $-20^{\circ} \mathrm{C}$ and defrosted one time before electrophoresis directly. Proteins were separated with PAG Electrophoresis in 7-17\% acrylamide gradient and then proteins were transferred with electric field $(10 \mathrm{~V} / \mathrm{cm})$ onto PVDF membrane. After blocking in 1\% BSA-PBS solution, the membrane was incubated with primary antibodies rabbit anti-GFAP (Santa Cruz, sc-9065), anti-NF- $\mathrm{KB}$ (Abcam, ab16502), anti-glucose-6-phosphate dehydrogenase (ab76598) (Abcam, ab76598), and anti-tubulin as a loading control (Abcam, ab15246) antibodies. Secondary anti-rabbit IgG antibodies conjugated with horse radish peroxidase (Abcam, ab6721) were used to probe the membrane of bound primary antibodies. Immunostaining was developed with luminol-hydrogen peroxide solution by the enhanced chemiluminescence method with the use of X-ray films (Konica Minolta, Japan). Densitometric analysis of immunostaining results was performed with the use of TotalLab TL120 software (USA). The intensity value obtai- ned via scanning every band was normalized to the intensity of correspondent tubulin band. Every track on the scanned picture was corrected to background level which corresponds to nonreactive area on the X-ray film.

Estimation of lipid peroxidation. The end products of lipid peroxidation MDA+4-hydroxialkenes were determined with the absorbance measuring of complex MDA-thiobarbituric acid by spectrophotometric method at $532 \mathrm{~nm}$. Tetraethoxypropane was used as the standard (Ohkawa et al., 1979).

Determination of intracellular ROS production. The production of intracellular general forms of ROS was determined with chloromethyldichlorodihydrofluorescein diacetate (DCFHDA). The cells were treated with $10 \mu \mathrm{M}$ DCFHDA and incubated $30 \mathrm{~min}$ at $37^{\circ} \mathrm{C}$. The measuring of ROS levels was performed with a SpectraMax Gemini EM spectrofluorometer with $485 \mathrm{~nm}$ wave length excitation and $530 \mathrm{~nm}$ emission.

Statistical analysis. Statistical comparisons of the data were performed with using a one-way analysis of variance (ANOVA) followed by Tukey's post-hoc test. Data are expressed as the $\mathrm{x} \pm \mathrm{SE}$ of at least four independent experiments. $\mathrm{P}$ values less than 0.05 were accepted as statistically significant.

\section{Results}

The results of cell viability measuring in the control and groups treated with $\mathrm{Cd}$ showed significant cytotoxic effect of $10 \mu \mathrm{M} \mathrm{CdCl}_{2}$ in primary rat astrocyte cell culture (Fig. 1a). However, the level of cell death in astrocytes exposed to both curcumin and $\mathrm{Cd}$ was decreased in comparison with Cd-treated astrocytes. It should be noted that treatment of primary rat astrocytes with curcumin alone had no meaningful effect on the index of cell viability. The results of intracellular ROS generation in control and all treated groups are presented in Figure $1 b$. Cd dose $10 \mu \mathrm{M}$ induced in astrocytes a statistical increase of general forms of ROS. The exposure to curcumin with doses 2 and $5 \mu \mathrm{M}$ didn't induce any changes of ROS content in primary astrocytes. Despite this isolated effect of curcumin, treatment with 2 and $5 \mu \mathrm{M}$ of curcumin provoked significant decrease of ROS level in Cd-treated astrocytes. The results of LPO index measuring are presented in Figure $1 c$. Cd exposure initiated in primary astrocyte cell culture the increment of end products of lipid peroxidation. In other hand, the exposure to curcumin in the abovementioned doses ameliorated the peroxidation process in astrocytes treated with $\mathrm{Cd}$.

The treatment the cells with $10 \mu \mathrm{M} \mathrm{CdCl}_{2}$ induced changes of GFAP content in primary astrocytes. GFAP expression in cells exposed to $\mathrm{Cd}$ was statistically decreased compared with untreated cells. The treatment of astrocytes with a doses 2 and $5 \mu \mathrm{M}$ of curcumin didn't initiate any visible with Western blot changes of GFAP content. However, the exposure to curcumin of astrocytes treated with $\mathrm{Cd}$ revealed the prevention of the lack of GFAP content (Fig. 2a).

The changes of G6PD in astrocytes modulated by $\mathrm{Cd}$, curcumin and combined $\mathrm{Cd}^{+}$curcumin treatment are presented in Figure $2 b$. The treatment with $10 \mu \mathrm{M} \mathrm{CdCl}_{2}$ suppressed G6PD expression. The pretreatment with curcumin ameliorated the harmful effect of $\mathrm{Cd}$. The inverse directed modulation of NF-kB p65 expression compared with GFAP and G6PD content was determined in astrocytes exposed to $\mathrm{Cd}$ and curcumin (Fig. 2c). The observed effect of curcumin on NF-kB suppression in primary astrocytes is related to the feature of this polyphenol to inhibit NF-kB family as was demonstrated earlier (Nedzvetsky et al., 2017).

The increase of NF-kB expression was observed in astrocytes exposed to $10 \mu \mathrm{M} \mathrm{CdCl}_{2}$. In spite of this depletion, curcumin improved the content of NF-kB p65. The level of the abovementioned proteins was normalized to tubulin content on the basis of literature data showing that the expression level of tubulin in neural tissue is more stable than other housekeeping markers.

\section{Discussion}

The results of present study demonstrate that $10 \mu \mathrm{M}$ dose of $\mathrm{CdCl}_{2}$ induce cell death in primary rat astrocyte cell culture. Moreover, decrease of astrocyte cell viability was accompanied with the increment of both intracellular ROS generation and growth of LPO. These detrimental effects of $\mathrm{Cd}$ could be related to glutathione depletion and a lack of 
antioxidant capacity of astrocytes, as it was determined in mouse primary astrocytes treated with $\mathrm{CdSO}_{4}$ (Im et al., 2006). Many cytotoxic effects of $\mathrm{Cd}$ are recognized as consequence of oxidative stress generation. However, Cd ion cannot participate in Warburg effect like iron. Thus, its detrimental effect could be linked in an indirect manner to initiation of ROS production as well as oxidative stress. One of key characters of $\mathrm{Cd}$ is a capability to bind SH-groups of proteins (Fotakis \& Timbrell, 2006). Taking into account that many enzymes and regulatory factors have a SH-containing active centre, $\mathrm{Cd}$ can inactivate them by binding.

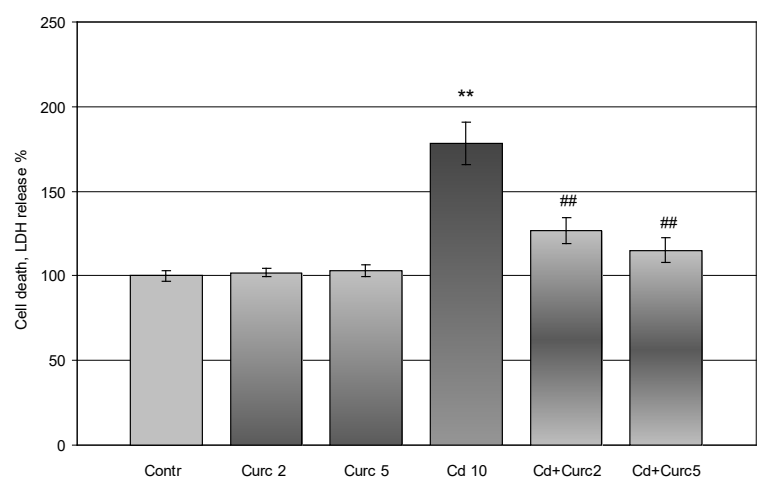

$a$
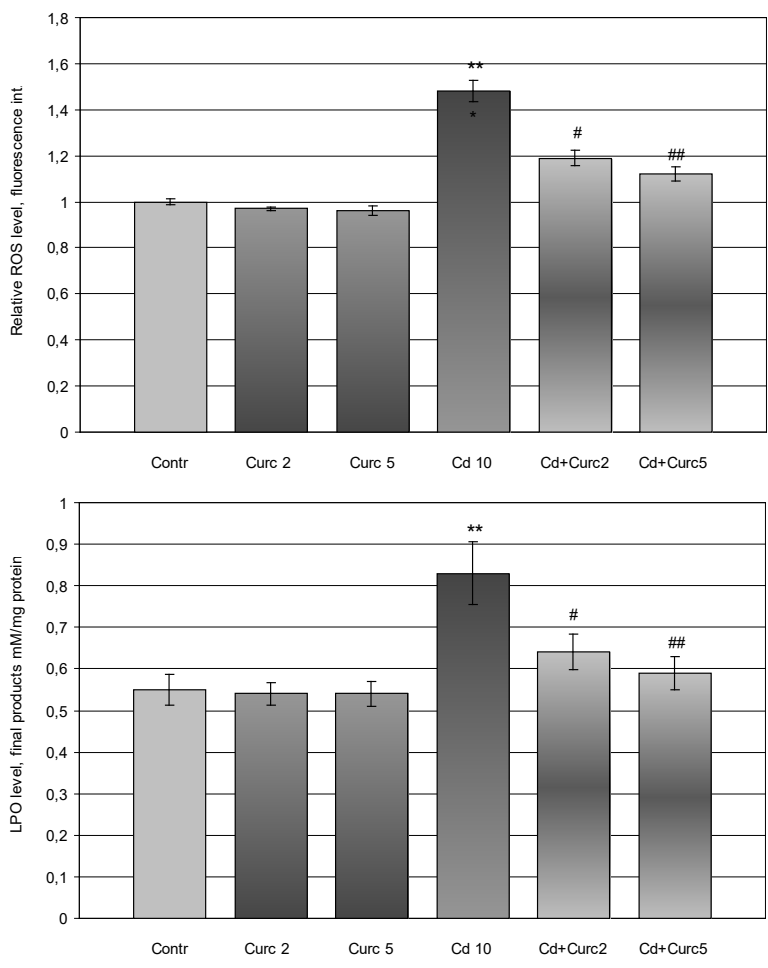

Fig. 1. The results of cell viability $(a)$, ROS (b) and LPO (c) levels in primary astrocytes cell culture in control, $\mathrm{Cd}$ and curcumin treated goups: Contr - control, Curc 2 - cells treated with $2 \mu \mathrm{M}$ curcumin, Curc $5-5 \mu \mathrm{M}$ curcumin, $C d-10 \mu \mathrm{M} \mathrm{CdCl}_{2}, C d+$ Curc2 $10 \mu \mathrm{M} \mathrm{CdCl}_{2}+2 \mu \mathrm{M}$ curcumin, $C d+$ Curc $5-10 \mu \mathrm{M} \mathrm{CdCl}_{2}+$

$5 \mu \mathrm{M}$ curcumin; $\mathrm{x} \pm \mathrm{SE} ; \mathrm{n}=6 ;{ }^{* *}-\mathrm{P}<0.01$ significance of differences compared with control group; ${ }^{\#}-\mathrm{P}<0.05,{ }^{\#}-\mathrm{P}<0.01$ compared with Cd-treated group

The data obtained in our study on glial intermediate filament suppression may reflect the indirect effect of $\mathrm{Cd}$ cytotoxicity toward this cytoskeleton subtype. Intermediate filaments in eukaryotic cells presented cell type specific proteins which possess the ability to polymerize without any enzymes. Intermediate filaments association was carried out due to the interaction between rod-domain of these cytoskeleton subunits which contain high number of SH-groups. Most of them are bound in intact filament structure, but these groups are continuously reducing during cytoskeleton rearrangement in metabolic active cells. Any toxic stimulus can initiate cellular response as well as activate metabolism.

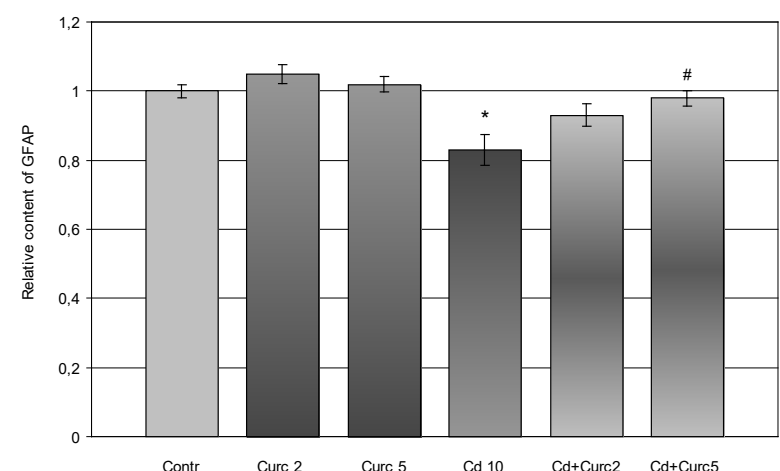

$a$

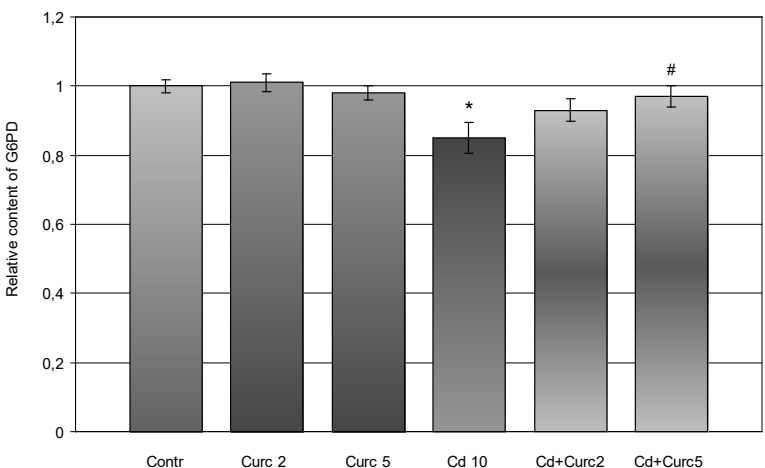

$b$

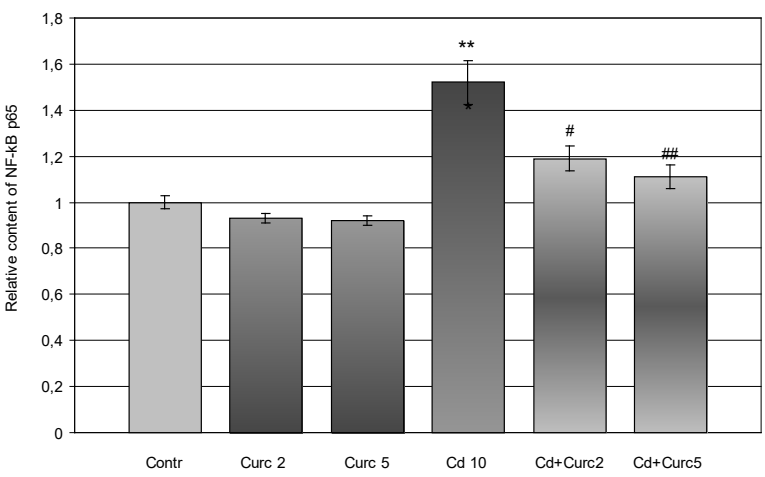

Fig 2. The results of the measuring of content of GFAP ( $a)$, G6PD $(b)$ and NF-kB $(c)$; the designations are according to Figure 1; $\mathrm{x} \pm \mathrm{SE}$; $\mathrm{n}=6 ;{ }^{*}-\mathrm{P}<0.05$ compared with control group, ${ }^{*}-\mathrm{P}<0.01$ significance of differences compared with control group,

${ }^{\#}-\mathrm{P}<0.05$ compared with $\mathrm{Cd}$-treated group, ${ }^{\#}-\mathrm{P}<0.01$ compared with Cd-treated group
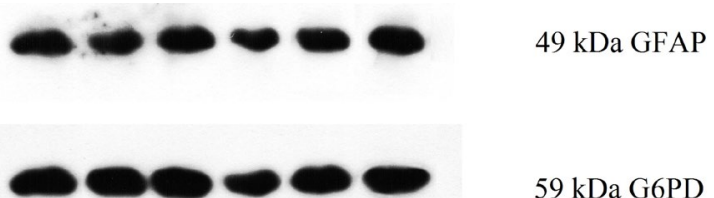

$59 \mathrm{kDa}$ G6PD
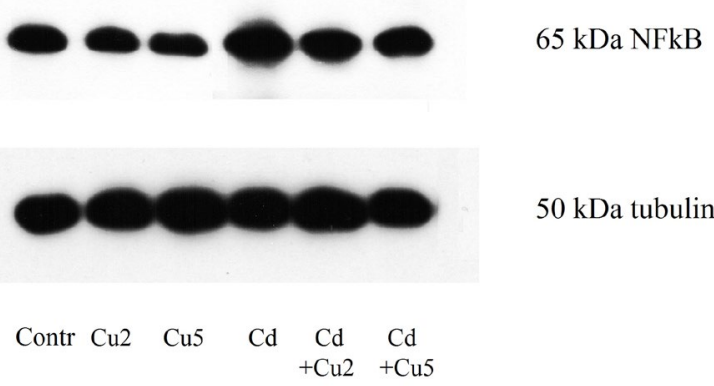

Fig. 3. The results of Western blot analyses of GFAP, G6PD, NF-kB and tubulin: the designations accord with Figure 1 
Thus, the decrease of GFAP expression in the study presented here could be linked to Cd capability to bind SH-group. NF-kB is considered as a transcriptional factor which controls both antioxidant and inflamematory cellular response (Lawrence, 2009; Chen et al., 2016). Several data show evidence that $\mathrm{Cd}$ can induce $\mathrm{NF}-\mathrm{kB}$ upregulation, correspondingly this pathway is directed to support cell viability. However, prolonged NF-kB stimulation as well as feedback between inflammation and oxidative stress products can promote adverse cellular events, regulatory pathways disturbance and switching to cell death. The obtained results showed that in primary astrocytes, 48 hours $\mathrm{Cd}$ exposure induced upregulation of NF-kB associated with cell death increment. On the other hand, pretreatment with curcumin significantly prevented these disturbances. Our result of NF-kB activation by cadmium exposure accords with data presented by Phuagkhaopong and coauthors in a study of cadmium chloride's effect in U-87 MG human astrocytoma cells and primary human (Phuagkhaopong et al., 2017). They have demonstrated increased secretion of interleukins IL-6 and IL-8, activation of NF-kB p65. But, unlike our results, $10 \mu \mathrm{M}$ dose of $\mathrm{CdCl}_{2}$ had minimal effects on cell morphology and viability. These observed differences could be explainned by the differences in vary sensitivity of the studied cell types in this work. The inhibitory effect of curcumin on transcriptional factors regulation have been demonstrated in various cancer cell lines, including colon cancer (Tong et al., 2016), colorectal cancer (Rajitha et al., 2016), hepatocellular carcinoma cells (Hsu et al., 2015), mice skin (Fattori et al., 2015), and in rat brains injured with hemorrhage and ischemia (Tu et al., 2014; Chang et al., 2015). Moreover, Purkayastha et al. (2009) showed the unique character of the soluble form of curcumin that can cross the blood-brain barrier and effectively suppress neuroinflammation as well as pro-inflammatory cytokines production. However, it does not inhibit the viability of normal brain cells.

Cellular response to toxic exposure requires metabolic energy consumption. G6PD is the key regulatory enzyme of the pentose phosphate pathway and controls glucose metabolism. G6PD plays a crucial role in cell growth and proliferation (Horecker et al., 2002). In our study we determined a statistical decrease of G6PD. A lack of G6PD in Cd exposed cells can be an important event in the pathogenetic chain which can decrease the cell viability. Thus, taking into account the obtained results we can speculate that $\mathrm{Cd}$ can inhibit primary astrocyte viability through glycolysis disturbance. The analysis of specific protein expression is a powerful approach to characterize molecular mechanisms of cytotoxicity initiated by various factors including environmental contaminants. Shekh and coauthors have presented qPCR data on the expression stability of housekeeping markers in rainbow trout, which is a widely used object to determine toxic effects of pollutants (Shekh et al., 2017). The results of acute exposure to cadmium $(\mathrm{Cd})$ and copper $(\mathrm{Cu})$ revealed differences in acknowledged housekeeping markers, especially $\beta$-actin, GAPDH, G6PD, ribosomal protein $\mathrm{L}_{8}$ etc. The stability of reference genes was dependent on the nature of metal ion and cell type.

However, the authors showed that $\mathrm{Cd}$ exposure can affect some housekeeping markers (Shekh et al., 2017). The result presented in our work accords with the above-mentioned data on modulation of G6PD expression by exposure to $\mathrm{Cd}$ ions. The obtained results of the glial intermediated filaments study showed the depletion of GFAP content in primary astrocytes cell culture exposed to $10 \mu \mathrm{M} \mathrm{CdCl}_{2}$ for 48 hours compared to untreated cells. The suppression of the astrocyte cytoskeleton by $\mathrm{Cd}$ could be accompanied by the vital function of this structural component in cellular response to cytotoxicity and can be one of causes of lack of cell viability. Astrocyte reactivity is regulated by a number of factors and is directed, as a rule, to repair the damages and to provide neural tissue cell viability (Guzyk et al., 2016). Despite this capability to protect brain tissue cells, the stimulation of excessive astrocyte reactivity can be deleterious to functional recovery of neurons to normal physiology. Excessive reactive astrogliosis can be a key cause of many neuronal dysfunctions including chronic inflammation and cytotoxic damage in the areas surrounding overactivated astrocytes.

Although, numerous factors in activation of astrocytes have been identified, the effect of several prevalent environmental pollutants remains unclear. As a rule, reactive astrogliosis is associated with overproduction of specific intermediate filaments protein GFAP which are unique in astrocytes. GFAP is considered the classic marker of reactive astrogliosis (Eng et al., 2000). Astrogliosis is accompanied with intensive growth of the inflammation which accompanied with many neurological diseases including Parkinson's and Alzheimer's disease as well as amyotrophic lateral sclerosis (Chen, 2016). The anti-inflammatory effect of curcumin is well-documented as one of main features of this natural non-toxic compound (Gullo et al., 2017). Thus, the detrimental effect of astrogliosis could be prevented with natural polyphenol compounds, especially curcumin (Yu et al., 2015). One more of the most important function of astrocytes is their involvement in blood-brain barrier (BBB) formation, integrity and remodeling. Both in vivo and in vitro studies support the role of astrocytes in the regulation of cerebral blood flow by means, in particular, of regulating endotheliocyte activity (Keaney \& Campbell, 2015). Wang \& Du (2013) presented data on the low or undetectable concentration of cadmium in the healthy human brain which is evidence of the strong function of the blood-brain barrier (BBB) in resisting $\mathrm{Cd}$ penetration. In spite of these findings, meaningful accumulation of $\mathrm{Cd}$ in the brain was demonstrated in heavy metal-exposed individuals and in patients with traumatic brain injury (Falnoga et al., 2000). Moreover, $\mathrm{Cd}$ can stimulate the overexpression of intercellular adhesion molecule-1 (ICAM-1), which is valid indicator of BBB injury in microvascular endothelial cells (Jeong et al., 2004). It should be noted that the final structure of the BBB is not fully developed in young vertebrate individuals (Cao et al., 2009). Thus, Cd neurotoxicity could bring a detrimental consequence in the early postnatal period and determine chronic CNS disorders.

$\mathrm{Cd}$ activates apoptotic pathway through the mitogen activated protein kinase (MAPK) induction, especially in brain endothelial cells (Jung et al., 2008). Several authors have shown the effect of $\mathrm{Cd}$ on induction of oxidative stress in rat astrocytes and release intracellular $\mathrm{Ca}^{2+}$ level and oxidative stress in rat astrocytes (Yang et al., 2008; Jo \& Koh, 2013). Taking into account that astrocytes and endothelial cells together form the $\mathrm{BBB}$, the role of these cell types in Cd-induced brain injury is critical in maintaining the barrier function of the BBB as well as brain homeostasis. The results on glial cytoskeleton depletion by $\mathrm{Cd}$ exposure obtained in the present study are evidence of a possible lack of astroglial barrier function in the brain. In other side, curcumin can maintain the viability of astrocytes through the improvement of cytoskeleton and glycolysis as one of metabolic energy sources. Cellular reactivity is a power-consuming process which requires ATP expenditure. The soluble form of curcumin easily interacts with soluble glycolytic enzymes to prevent $\mathrm{Cd}$ having a detrimental effect on astrocytes.

Solubility of curcumin is extremely important for bioavailability of this polyphenol, especially in neural tissue which is surrounded by the BBB. The results presented in our study are evidence that soluble curcumin develops a neuroprotective effect compared with hydrophobic tumeric forms of curcumin (Ullah et al. 2017). The results presented in our work show that the soluble form of curcumin prevents cytoskeleton depletion as well as deficiency of the key enzyme of the glucose utilizetion pathway. Thus, the soluble form of curcumin tested in our study possess a significant neuroprotective effect directed on astrocyte cytoskeleton and metabolic energy production.

Recently, Mori et al. (2015) have demonstrated the effect of Cd on cytoskeleton and morphology of neural stem/progenitor cells. Subcytotoxic $\mathrm{Cd}$ concentration can induce disturbance of progenitor cells morphology which reflects neurodevelopmental cytotoxicity of $\mathrm{Cd}$ exposure (Mori et al., 2015). The results on astrocyte cytoskeleton rearrangement observed in our study correspond with the effect of $\mathrm{Cd}$ on neural progenitor cells presented by Mori and coauthors.

\section{Conclusions}

Taking together, the results obtained in our study allow us to conclude that $10 \mu \mathrm{M} \mathrm{Cd}$ can induce cytotoxicity in astrocytes which is accompanied by a lack of cell viability, the depletion of cytoskeleton and glycolysis inhibition. Moreover, the treatment with a soluble form of curcumin significantly prevented the abovementioned disturbances. Thus, low doses of soluble curcumin possess a neuroprotective effect directed to support astroglial functions. Taking into account that soluble 
curcumin can permeate the BBB, this polyphenol could be applied in low doses as a neuroprotector.

\section{References}

Acan, N. L., \& Tezcan, E. F. (1995). Inhibition kinetics of sheep brain glutathione reductase by cadmium ion. Biochemical and Molecular Medicine, 54, 33-37.

Al-Jassabi, S., Ahmed, K. A., \& Ameen, M. (2012). Antioxidant effect of curcumin against microcystin-LR-induced renal oxidative damage in Balb/c mice. Tropical Journal of Pharmaceutical Research, 11, 531-536.

Baiomy, A. A., \& Mansour, A. A. (2016). Genetic and histopathological responses to cadmium toxicity in rabbit's kidney and liver: Protection by ginger (Zingiber officinale). Biological Trace Element Research, 170(2), 320-329.

Bereswill, S., Muñoz, M., Fischer, A., Plickert, R., Haag, L., Otto, B., Kühl, A., Loddenkemper, C., Göbel, U., \& Heimesaat, M. (2010). Anti-inflammatory effects of resveratrol, curcumin and simvastatin in acute small intestinal inflammation. PLoS One, 12(5), 3-15.

Bhullar, K. S., Jha, A., Youssef, D., \& Rupasinghe, H. P. (2013). Curcumin and its carbocyclic analogs: Structure-activity in relation to antioxidant and selected biological properties. Molecules, 18(5), 5389-5404.

Bradford, M. M. (1976). Rapid and sensitive method for the quantitation of microgram quantities of protein utilizing the principle of protein-dye binding. Analytical Biochemistry, 72, 248-254.

Buosi, A. S., Matias, I., Araujo, A. B., Batista, C., \& Gomes, F. (2018). Heterogeneity in synaptogenic profile of astrocytes from different brain regions. Molecular Neurobiology, 55(1), 751-762.

Cao, Y., Chen, A., \& Radcliffe, J. (2009). Postnatal cadmium exposure, neurodevelopment, and blood pressure in children at 2, 5, and 7 years of age. Environmental Health Perspectives, 117(10), 1580-1586.

Chang, C. Z., Wu, S. C., Lin, C. L., \& Kwan, A. L. (2015). Curcumin, encapsulated in nano-sized PLGA, down-regulates nuclear factor $\mathrm{\kappa B}(\mathrm{p} 65)$ and subarachnoid hemorrhage induced early brain injury in a rat model. Brain Research, 1608, 215-224.

Chen, W. W., Zhang, X., \& Huang, W. J. (2016). Role of neuroinflammation in neurodegenerative diseases (review). Molecular Medicine Reports, 13(4), 3391-3396.

Ciesielski, T. H., Schwartz, J., Bellinger, D. C., Hauser, R., Amarasiriwardena, C., Sparrow, D., \& Wright, R. O. (2018). Iron-processing genotypes, nutrient intakes, and cadmium levels in the normative aging study: Evidence of sensifive subpopulations in cadmium risk assessment. Environment International, $119,527-535$.

Ciesielski, T., Bellinger, D. C., Schwartz, J., Hauser, R., \& Wright, R. O. (2013). Associations between cadmium exposure and neurocognitive test scores in a cross-sectional study of US adults. Environmental Health Perspectives, 16(1), 7-19.

Ciesielski, T., Weuve, J., Bellinger, D. C., Schwartz, J., Lanphear, B., \& Wright, R. O. (2012). Cadmium exposure and neurodevelopmental outcomes in U.S. children. Environmental Health Persectives, 120(5), 758-763.

Eng, L. F, Ghimikar, R. S., \& Lee, Y. L. (2000). Glial fibrillary acidic protein: GFAP-thirty-one years (1969-2000). Neurochemical Research, 25(9-10), 1439-1451.

Falnoga, I., Tusek-Znidaric, M., Horvat, M., \& Stegnar, P. (2000). Mercury, selenium, and cadmium in human autopsy samples from Idrija residents and mercury mine workers. Environmental Research, 84(3), 211-218.

Farina, M., Avila, D. S., da Rocha, J. B., \& Aschner, M. (2013). Metals, oxidative stress and neurodegeneration: A focus on iron, manganese and mercury. Neurochemistry International, 62(5), 575-594.

Fattori, V., Pinho-Ribeiro, F. A., Borghi, S. M., Alves-Filho, J. C., Cunha, T. M., Cunha, F. Q., Casagrande, R., \& Verri, W. A. (2015). Curcumin inhibits superoxide anion-induced pain-like behavior and leukocyte recruitment by increasing Nrf2 expression and reducing NF-kB activation. Inflammation Research, 64(12), 993-1003.

Fotakis, G., \& Timbrell, J. A. (2006). Modulation of cadmium chloride toxicity by sulphur amino acids in hepatoma cells. Toxicology in Vitro, 20(5), 641-648.

Freeman, M. R. (2010). Specification and morphogenesis of astrocytes. Science, $330,774-778$

Fujiwara, Y., Lee, J. Y., Tokumoto, M., \& Satoh, M. (2012). Cadmium renal toxicity via apoptotic pathways. Biological and Pharmaceutical Bulletin, 35, 1892-1897.

García-Niño, W. R., \& Pedraza-Chaverrí, J. (2014). Protective effect of curcumin against heavy metals-induced liver damage. Food and Chemical Toxicology, 69, 182-201.

Gullo, F., Ceriani, M., Aloia, A., Wanke, E., Constanti, A., Costa, B., \& Lecchi, M. (2017). Plant polyphenols and exendin-4 prevent hyperactivity and TNF-a release in LPS-treated in vitro neuron/astrocyte/microglial networks. Frontiers in Neuroscience, 11, 1502-1513.
Guzyk, M. M., Tykhomyrov, A. A., \& Nedzvetsky, V. S. (2016). Poly(ADP-ribose) polymerase-1 (PARP-1) inhibitors reduce reactive gliosis and improve angiostatin levels in retina of diabetic rats. Neurochemical Research, 41(10), 2526-2537.

Horecker, B. L. (2002). The pentose phosphate pathway. Journal of Biological Chemistry, 277, 47965-47971.

Hsu, F. T., Liu, Y. C., Liu, T. T., \& Hwang, J. J. (2015). Curcumin sensitizes hepatocellular carcinoma cells to radiation via suppression of radiationinduced NF-kB activity. BioMed Research International, 215, 363-370.

Huang, Y., Chao, K. S., Liao, H., \& Chen, Y. (2013). Targeting sonic hedgehog signaling by compounds and derivatives from natural products. EvidenceBased Complementary and Alternative Medicine, 74, 85-97.

Im, J. Y., Park, S. G., \& Han, P. L. (2006). Cadmium-induced astroglial death proceeds via glutathione depletion. Journal of Neuroscience Research, 83(2), 301-308.

Järup, L., \& Akesson, A. (2009). Current status of cadmium as an environmental health problem. Toxicology and Applied Pharmacology, 238, 201-208.

Jeong, E. M., Moon, C. H., Kim, C. S., Lee, S. H., Baik, E. J., Moon, C. K., \& Jung, Y. S. (2004). Cadmium stimulates the expression of ICAM-1 via NFkappaB activation in cerebrovascular endothelial cells. Biochemical and Biophysical Research Communications, 320, 887-892.

Jo, C., \& Koh, Y. H. (2013). Cadmium induces N-cadherin cleavage via ERKmediated $\gamma$-secretase activation in C6 astroglia cells. Toxicology Letters, 222, $117-121$.

Jung, Y. S., Jeong, E. M., Park, E. K., Kim, Y. M., Sohn, S., Lee, S. H., Baik, E. J., \& Moon, C. H. (2008). Cadmium induces apoptotic cell death through p38 MAPK in brain microvessel endothelial cells. European Journal of Pharmacology, 578, 11-18.

Kamphuis, W., Kooijman, L., Orre, M., Stassen, O., Pekny, M., \& Elly, M. H. (2015). GFAP and vimentin deficiency alters gene expression in astrocytes and microglia in wild-type mice and changes the transcriptional response of reactive glia in mouse model for Alzheimer's disease. Glia, 63(6), 201-218.

Keaney, J., \& Campbell, M. (2015). The dynamic blood-brain barrier. FEBS Journal, 282, 4067-4079.

Kutluay, S. B., Doroghazi, J., Roemer, M. E., \& Triezenberg, S. J. (2008). Curcumin inhibits herpes simplex virus immediate-early gene expression by a mechanism independent of $\mathrm{p} 300 / \mathrm{CBP}$ histone acetyltransferase activity. Virology, 373, 239-247.

Lawrence, T. (2009). The nuclear factor NF-kappaB pathway in inflammation, Cold Spring Harbor Perspectives in Biology, 6, 16-31.

Lee, J. Y., Tokumoto, M., Hattori, Y., Fujiwara, Y., Shimada, A., \& Satoh, M. (2016). Different regulation of p53 expression by cadmium exposure in kidney, liver, intestine, vasculature, and brain astrocytes. Toxicology Research, 32(1), $73-80$.

Liu, C., Cui, G., Zhu, M., Kang, X., \& Guo, H. (2014). Neuroinflammation in Alzheimer's disease: Chemokines produced by astrocytes and chemokine receptors. International Journal of Clinical and Experimental Pathology, $7(12), 8342-8355$.

Liu, L., Sun, L., Wu, Q., Guo, W., Li, L., Chen, Y., Li, Y., Gong, C., Qian, Z., \& Wei, Y. (2013). Curcumin loaded polymeric micelles inhibit breast tumor growth and spontaneous pulmonary metastasis. International Journal of Pharmaceutics, 443(1-2), 175-182.

Maele-Fabry, G., Lombaert, N., \& Lison, D. (2016). Dietary exposure to cadmium and risk of breast cancer in postmenopausal women: A systematic review and meta-analysis. Environment International, 86, 1-13.

Marini, E., Di Giulio, M., Magi, G., Di Lodovico, S., Cimarelli, M. E., Brenciani, A., Nostro, A., Cellini, L., \& Facinelli, B. (2018). Curcumin, an antibiotic resistance breaker against a multiresistant clinical isolate of Mycobacterium abscessus. Phytotherapy Research, 32(3), 488-495.

Mendez-Armenta, M., \& Rios, C. (2007). Cadmium neurotoxicity. Environmental Toxicology and Pharmacology, 23(3), 350-358.

Mohajeri, M., Rezaee, M., \& Sahebkar, A. (2017). Cadmium-induced toxicity is rescued by curcumin: A review. Biofactors, 43(5), 645-661.

Mori, H., Sasaki, G., Nishikawa, M., \& Hara, M. (2015). Effects of subcytotoxic cadmium on morphology of glial fibrillaryacidic protein network in astrocytes derived from murine neuralstem/progenitor cells. Environmental Toxicology and Pharmacology, 40, 639-644.

Nair, A. R., Degheselle, O., Smeets, K., Van Kerkhove, E., \& Cuypers, A. (2013). Cadmium-induced pathologies: Where is the oxidative balance lost (or not). International Journal of Molecular Sciences, 14, 6116-6143.

Nedzvetsky, V. S., Tuzcu, M., Yasar, A., Tikhomirov, A. A., \& Baydas, G. (2006) Effects of vitamin $\mathrm{E}$ against aluminum neurotoxicity in rats. Biochemistry (Moscow), 71(3), 239-244.

Nedzvetsky, V., Agca, C. A., \& Kyrychenko, S. (2017). Neuroprotective effect of curcumin on LPS-activated astrocytes is related to the prevention of GFAP and NF-אB upregulation. Neurophysiology, 49(4), 305-307. 
Neuhaus, W., Gaiser, F., Mahringer, A., Franz, J., Riethmüller, C., \& Förster, C. (2014). The pivota lrole of astrocytes in an in vitro stroke model of the bloodbrain barrier. Frontiers in Cellular Neuroscience, 8, 352-365.

Nilesh, M. Kalariya, A., Nancy, K., Wills, B., Kota, V., Ramana, C., Satish, K., Srivastava, C., Frederik, J. G., \& Van Kuijk, M. (2009). Cadmium-induced apoptotic death of human retinal pigment epithelial cells is mediated by MAPK pathway. Experimental Eye Research, 89, 494-502.

Ninkov, M., Popov, A., Aleksandrov, A., Demenesku, J., Mirkov, I., Mileusnic, D., Petrovic, A., Grigorov, I., Zolotarevski, L., Tolinacki, M., Kataranovski, D., Brceski, I., \& Kataranovski, M. (2015). Toxicity of oral cadmium intake: Impact on gut immunity. Toxicology Letters, 237, 89-99.

Ohkawa, H., Ohishi, N., \& Yagi, K. (1979). Assay for lipid peroxides in animal tissues by thiobarbituric acid reaction. Analytical Biochemistry, 95, 351-358.

Owens, R., Grabert, K., Davies, C. L., Alfieri, A., Antel, J. P., Healy, L. M., \& McColl, B. W. (2017). Divergent neuroinflammatory regulation of microglial TREM expression and involvement of NF- $\mathrm{kB}$. Frontiers in Cellular Neuroscience, 11, 56-68.

Pekny, M., Wilhelmsson, U., \& Pekna, M. (2014). The dual role of astrocyte activation and reactive gliosis. Neuroscience Letters, 565, 30-38.

Phuagkhaopong, S., Ospondpant, D., Kasemsuk, T., Sibmooh, N., Soodvilai, S., Power, C., \& Vivithanaporn, P. (2017). Cadmium-induced IL-6 and IL-8 expression and release from astrocytes are mediated by MAPK and NF- $\mathrm{KB}$ pathways. Neurotoxicology, 60, 82-91.

Poliandri, A. H., Cabilla, J. P., Velardez, M. O., Bodo, C. C., \& Duvilanski, B. H. (2003). Cadmium induces apoptosis in anterior pituitary cells that can be reversed by treatment with antioxidants. Toxicology and Applied Pharmacology, 190, 17-24.

Priyadarsini, K. I. (2014). The chemistry of curcumin: From extraction to therapeutic agent. Molecules, 19, 2091-2112.

Purkayastha, S., Berliner, A., Fernando, S. S., Ranasinghe, B., Ray, I., Tariq, H., \& Banerjee, P. (2009). Curcumin blocks brain tumor formation. Brain Research, $1266,130-138$.

Rajitha, B., Belalcazar, A., Nagaraju, G. P., Shaib, W. L., Snyder, J. P., Shoji, M., Pattnaik, S., Alam, A., \& El-Rayes, B. F. (2016). Inhibition of NF-кB translocation by curcumin analogs induces $\mathrm{G}_{0} / \mathrm{G}_{1}$ arrest and downregulates thymidylate synthase in colorectal cancer. Cancer Letters, 373(2), 227-233.

Shekh, K., Tang, S., Niyogi, S., \& Hecker, M. (2017). Expression stability and selection of optimal reference genes for gene expression normalization in early life stage rainbow trout exposed to cadmium and copper. Aquatic Toxicology, $190,217-227$.

Shukla, G. S., Hussain, T., Srivastava, R. S., \& Chandra, S. V. (1989). Glutathione peroxidase and catalase in liver, kidney, testis and brain regions of rats following cadmium exposure and subsequent withdrawal. Industrial Health, 27, 59-69.
Strasser, E. M., Wessner, B., Manhart, N., \& Roth, E. (2005). The relationship between the anti-inflammatory effects of curcumin and cellular glutathione content in myelomonocytic cells. Biochemistry Pharmacology, 70, 552-559.

Swiergosz-Kowalewska, R. (2001). Cadmium distribution and toxicity in tissues of small rodents. Microscopy Research and Technique, 55, 208-222.

Tandon, S. K., Singh, S., Prasad, S., Khandekar, K., Dwivedi, V. K., Chatterjee, M., \& Mathur, N. (2003). Reversal of cadmium induced oxidative stress by chelating agent, antioxidant or their combination in rat. Toxicology Letters, $145,211-217$

Taylor, M., Moore, S., Mourtas, S., Niarakis, A., Re, F., Zona, C., La Ferla, B., Nicotra, F., Masserini, M., Antimisiaris, S. G., Gregori, M., \& Allsop, D. (2011). Effect of curcumin-associated and lipid ligand-functionalized nanoliposomes on aggregation of the Alzheimer's A $\beta$ peptide. Nanomedicine, 7(5), $541-550$.

Tong, W., Wang, Q., Sun, D., \& Suo, J. (2016). Curcumin suppresses colon cancer cell invasion via AMPK-induced inhibition of NF- $\mathrm{KB}$, uPA activator and MMP9. Oncology Letters, 12(5), 4139-4146.

Tu, X. K., Yang, W. Z., Chen, J. P., Chen, Y., Ouyang, L. Q., Xu, Y. C., \& Shi, S. S. (2014). Curcumin inhibits TLR2/4-NF- $\mathrm{BB}$ signaling pathway and attenuates brain damage in permanent focal cerebral ischemia in rats. Inflammation, 37(5), 1544-1551.

Ullah, F., Liang, A., Rangel, A., Gyengesi, E., Niedermayer, G., \& Münch, G. (2017). High bioavailability curcumin: an anti-inflammatory and neurosupportive bioactive nutrient for neurodegenerative diseases characterized by chronic neuroinflammation. Archives of Toxicology, 91(4), 1623-1634.

Waisberg, M., Joseph, P., Hale, B., \& Beyersmann, D. (2003). Molecular and cellular mechanisms of cadmium carcinogenesis. Toxicology, 192 (2-3), 95-117.

Wang, B., \& Du, Y. (2013). Cadmium and its neurotoxic effects. Oxidative Medicine and Cellular Longevity, 5, 898-910.

Wang, L., Shen, Y., Song, R., Sun, Y., Xu, J., \& Xu, Q. (2009). An anticancer effect of curcumin mediated by down-regulating phosphatase of regenerating liver-3 expression on highly metastatic melanoma cells. Molecular Pharmacology, 76, 1238-2178.

Yang, C. S., Tzou, B. C., Liu, Y. P., Tsai, M. J., Shyue, S. K., \& Tzeng, S. F. (2008). Inhibition of cadmium-induced oxidative injury in rat primary astrocytes by the addition of antioxidants and the reduction of intracellular calcium. Journal of Cellular Biochemistry, 103, 825-834.

Yogosawa, S., Yamada, Y., Yasuda, S., Sun, Q., Takizawa, K., \& Sakai, T. (2012). Dehydrozingerone, a structural analogue of curcumin, induces cell-cycle arrest at the $\mathrm{G}_{2} / \mathrm{M}$ phase and accumulates intracellular ROS in HT-29 human colon cancer cells. Journal Natural Products, 75(12), 2088-2093.

Yu, B., Changsheng, Y., Wenjun, Z., Ben, L., Hai, Q., Jing, M., Guangwei, X., Shuhua, W., Fang, L., Aschner, M., \& Rongzhu, L. (2015). Differential protection of pre-versus post-treatment with curcumin, trolox, and N-acetylcysteine against acrylonitrile-induced cytotoxicity in primary rat astrocytes. Neurotoxicology, 51, 58-66. 